\title{
Evaluation of Serum Ischemia Modified Albumin Level among preterm infants with Necrotizing Enterocolitis
}

\author{
A.M.Shaheen ${ }^{1}$, R.Abd El-Hakeem ${ }^{1}$, S.M.Fayed ${ }^{2}$ and M.I.Abd El-Monem ${ }^{1}$ \\ ${ }^{1}$ Pediatrics and Neonatology, Dept., Faculty of Medicine, Benha Univ., Benha, Egypt \\ ${ }^{2}$ Clinical and Chemical Pathology, Dept., Faculty of Medicine, Benha Univ., Benha, Egypt
}

E-mail:

\begin{abstract}
Background: Enterocolitis necrotizing (NEC) is linked to oxidative stress and ischemical necrosis. Ischemia modified albumin (IMA) is an albumin produced by reactive oxygen species that develop during ischemia owing to albumin modifications. Aim: to assess the amount of IMA in NEC-diagnosed preterm babies and to compare their level of healthy control. Methods and Subjects: Group (A) comprised thirty preterm babies with NEC, (B) included a control group of thirty preterm babies. The NEC diagnosis was established by Bell's amended staging criteria and ELISA assessed serum IMA in all subjects. Results: There was a substantial difference between patients and control groups (group A and B) in gestational age, sex and weight. There was a substantial difference in IMA levels between patients and control groups $(\mathrm{P}<0.0001)$. The following have significantly unfavourable associations; NEC gravity and weight of patients $(\mathrm{P}<0.0001)$ The severity of the NEC and the level of the haemoglobin $(\mathrm{P}<0.00001)$, the seriousness of the NEC and the platelet $(\mathrm{P}<0.00001)$. Significant negative associations existed between IMA levels, gestational age $(\mathrm{P}<0.0001)$ and IMA levels and weight $(\mathrm{P}<0.00001)$. The following connections have been significantly positive; IMA levels and onset age $(\mathrm{P}<0.00001)$; and lastly IMA and NEC severity $(\mathrm{P}<0.00001)$. Conclusion: During the course of the illness, the NEC is typically identified using clinical and abdominal $\mathrm{X}$-ray evidence. Thus one of the greatest difficulties for the diagnosis and treatment of NEC was the lack of a consistent, accurate and early marker of intestinal inflammation in the peripheral blood. In addition to radiological studies, the diagnosis of NEC does not include accurate biochemical assays in clinical practise. The present research shows that IMA may be involved in NEC's early diagnosis.
\end{abstract}

\section{Keywords:}

\section{Introduction}

Enterocolitis (NEC) necrotizing is the main cause of gastrointestinal mortality in preterm babies [1].

It is characterised by inflammation and damage to the gut wall barrier which may lead to necrosis and, possibly, intestinal perforation. [2]

Multifactorial pathophysiology is considered. The only risk factors for NEC have been consistently documented are formula feeding, intestinal dysbiosis, low birth weight and anticipation. [3] Coagulation or ischemical necrosis as indicated is the histopathologic characteristic of NEC. [4] The typical NEC patient is a preterm baby that thrives but suddenly has feeding resistance, abdominal distension, blood supplies and symptoms of sepsis (changes in heart rate, respiratory rate, temperature and blood pressure) [5]

The albumin Ischemia modified is an albumin that has a changed $\mathrm{N}$-terminal owing to ischemic effects. [6]

The IMA takes place because of changes in the albumin produced by reactive oxygen species occurring during ischemia. Some clinical trials have recommended the use of IMA for the early detection of myocardial ischemia[6], stroke[7], acute mesenteric ischemia [8].

\section{Subjects and Methods}

This is a case and control study. This study was conducted on thirty preterm infants with diagnosis of NEC as group (A). The study also included thirty healthy preterm infants as a control group (group B). They were selected from pediatrics and neonatology department of Benha University hospitals and Benha Children hospital from January 2020 to January 2021.

The study included preterm infants with gestational age less than 37 weeks with NEC. Any patient with any of the following conditions was excluded from the study: congenital anomalies, exchange transfusions or neural tube defects. Human Ischemia Modified Albumin (IMA) ELISA Kit was used to assay the IMA in the sample of human's serum.

\subsection{Statistical Analysis}

The statistical analysis was done using the computer program Statistical Package for the Social Sciences (SPSS). Qualitative data were presented as number and percentages, while quantitative data with parametric distribution were presented as mean, standard deviations (SD), and ranges. Student's $t$ test was used for numerical variables of normally distributed samples. The $\mathrm{P}$ values $<.05$ were considered statistically significant. 


\section{Results}

Table (1) Demographic data.

\begin{tabular}{lcccc}
\hline & Group (A) & Group (B) & T-test & Significance \\
\hline $\begin{array}{l}\text { Gestational age } \\
\text { (weeks) }\end{array}$ & $31.47 \pm 1.70$ & $31.83 \pm 1.56$ & 0.8546 & $\mathrm{P}=0.3963$ \\
Sex & $53.33 \% * *$ & $50 \%$ & 0.065 & $\mathrm{P}=0.7980$ \\
Weight (Grams) & $1378.17 \pm 169.73$ & $1432.37 \pm 131.88$ & 0.2522 & $\mathrm{P}=0.8018$ \\
\hline
\end{tabular}

The patients and control groups (group A and B) showed a non-significant difference as regards gestational age, sex and weight table (1).

The IMA was measured in serum of patients and control groups. There was a significant difference between patients and control groups as regards the IMA levels $($ Mean $\pm \mathrm{SD}=134.97 \pm 18.98,60.49 \pm$ 11.01 respectively; $\mathrm{P}<0.0001)$.

There were significant negative correlations between the following; NEC severity and patients' weight $(r=-0.9336, \mathrm{P}<0.0001)$ NEC severity and hemoglobin concentration $(\mathrm{r}=-0.9594, \mathrm{P}<0.00001)$, NEC severity and Platelet count $(r=-0.9477, P<$ $0.00001)$, and finally NEC severity and Na level ( $\mathrm{r}=$ $0.9298, \mathrm{P}<0.00001)$.

There were significant negative correlations between the following; IMA levels and patients' gestational age $(\mathrm{r}=-0.8943, \mathrm{P}<0.0001)$ and IMA levels and weight $(\mathrm{r}=-0.9031, \mathrm{P}<0.00001)$. There were significant positive correlations between the following; IMA levels and age of onset $(r=0.7034, \mathrm{P}$ $<0.00001)$, and finally IMA level and NEC severity $(r=0.9624, \mathrm{P}<0.00001)$.

\section{Discussion}

The NEC is a severe premature complication. NEC is the main cause of mortality for $5-12 \%$ of born neonates with a very low birth weight (VLBW; $<1500 \mathrm{~g}$ ) (Hall et al., 2013) Hall 9. IMA is an FDA approved early myocardial ischemia diagnostic indicator for individuals with acute coronary artery syndrome [10].

The present research showed significant differences in IMA $(\mathrm{P}<0,0001)$ between patients and control groups. This corresponds to [11] which assessed 37 NEC patients and included them as the study group. The control group included thirty-six individuals without NEC symptoms. Serum levels of IMA were considerably greater in the NEC group ( $\mathrm{P}$ $<0.001)$ than in the control group.

Patel et al., (2016)[12] observed that the estimated incidence of NEC in VLBW babies with severe anaemia $(\mathrm{P}=0.002)$ is greater. A strong negative association between NEC gravity and concentration of haemoglobin has been found in the present research $(\mathrm{P}<0,00001)$

There was also a strong negative connection between the severity of the NEC and the number of plateles $(\mathrm{P}<0.00001)$. This is similar with [13] who showed decreased platelet count in individuals with more severe illness $(\mathrm{P}=0.012)$.
The sluggish and delayed rise in CRP makes it unworkable, since many NEC cases develop quicker than time for the CRP [14]. For health care providers, the search for a highly sensitive, precise ideal marker in NEC is a problem. The NEC diagnosis showed a high level of sensitivity and specificity for IMA (94.7\% and 92\%) [15].

\section{Conclusion}

During illness development, the NEC is typically identified by clinical and abdominal radiographical signs. Thus one of the greatest difficulties for the diagnosis and treatment of NEC was the lack of a consistent, accurate and early marker of intestinal inflammation in the peripheral blood.

In addition to radiological studies, the diagnosis of NEC does not include accurate biochemical assays in clinical practise. The present research shows that IMA may be involved in NEC's early diagnosis.

\section{References}

[1] S.Papillon, S.L.Castle, C.P.Gayer, and H.R.Ford. Necrotizing enterocolitis: contemporary management and outcomes. Adv. Pediatr.vol.60,pp.263-279,2013.

[2] P.K.Yajamanyam, S.V.Rasiah, and A.K.Ewer. Necrotizing enterocolitis:current perspectives. Res. Rep. Neonatol.vol. 4,pp.31-42,2014.

[3] A.T.Rose, and R.M.Patel. A critical analysis of risk factors for necrotizing enterocolitis. Semin. Fetal Neonatal Med.vol.23(6),pp.374-9,2018.

[4] K.L.Schnabl, J.E.Van Aerde, A.B.Thomson, and M.T.Clandinin. Necrotizing enterocolitis: a multifactorial disease with no cure. World J. Gastroenterol.vol.14(14),pp.2142-61,2008.

[5] A.Elfvin, E.Dinsdale, P.W.Wales, and A.M.Moore. Low birthweight, gestational age, need for surgical intervention and gramnegative bacteraemia predict intestinal failure following necrotising enterocolitis. Acta. Paediatr.vol. 104,pp.771-776, 2015.

[6] D.C.Gaze. Ischemia modified albumin: a novel biomarker for the detection of cardiac ischemia. Drug Metab. Pharmacokinet.vol.24,pp.333-341,2009.

[7] A.Gunduz, S.Turedi, A.Mentese, V.Altunayoglu, I.Turan, S.C.Karahan, M.Topbas, M.Aydin, I.Eraydin, and B.Akcan. Ischemia- modified albumin levels in 
cerebrovascular accidents. Am. J. Emerg. Med.vol. 26,pp.874-878,2008.

[8] Z.D.Dundar, B.Cander, M.Gul, K.U.Karabulut, and S. Girisgin. Serum ischemia- modified albumin levels in an experimental acute mesenteric ischemia model. Acad. Emerg. Med.vol. 17,pp.1233$1238,2010$.

[9] N.J.Hall, S.Eaton, and A.Pierro. Necrotizing enterocolitis: prevention, treatment, and outcome. J. Pediatr. Surg.vol. 48,pp.23592367,2013 .

[10] M.Montagnana, G.Lippi, N.Tessitore, G.L.Salvagno, G.Targher, M.Gelati, A. Lupo, and G.C.Guidi. Effect of hemodialysis on traditional and innovative cardiac markers. J. Clin. Lab. Anal.vol.22(1),pp.59-65,2008.

[11] I.Yakut, C.Tayman, O.Oztekin, M.Namuslu, F.Karaca, and A.Kosus. Ischemia-modified albumin may be a novel marker for the diagnosis and follow-up of necrotizing enterocolitis. Journal of Clinical Laboratory Analysis.vol. 28(3),pp.170$177,2014$.

[12] R.M.Patel, A.Knezevic, N.Shenvi, M.Hinkes, S.Keene, J.D.Roback, K.A.Easley, and C.D.Josephson. Association of Red Blood Cell Transfusion, Anemia, and Necrotizing Enterocolitis in Very Low-BirthWeight Infants. JAMA.vol.315(9),pp.889$897,2016$.

[13] M.Ververidis, E.M.Kiely, L.Spitz, D.P.Drake, S.Eaton, and A.Pierro. The clinical significance of thrombocytopenia in neonates with necrotizing enterocolitis. J. Pediatr. Surg.vol.36(5),pp.799-803,2001.

[14] B.D.Garg, D.Sharma, and A.Bansal. Biomarkers of necrotizing enterocolitis: a review of literature. J Matern Fetal Neonatal Med.vol. 31(22),pp.3051-3064,2018.

[15] G.Terrin, L.Stronati, S.Cucchiara, and M.De Curtis. Serum Markers of Necrotizing Enterocolitis: A Systematic Review. J Pediatr Gastroenterol Nutr.vol.65(6),pp.e120-e132. ,2017. 